\title{
Responding to Pandemics: What We've Learned from HIV/AIDS
}

\author{
Ronald O. Valdiserri ${ }^{1} \cdot$ David R. Holtgrave ${ }^{2}$
}

Published online: 9 April 2020

(c) Springer Science+Business Media, LLC, part of Springer Nature 2020

To state the obvious, we are in the midst of a global pandemic. Like SARS and MERS before it, a new coronavirus (SARS-CoV-2) that was previously confined to an animal species, has made its way into the human population with devastating results [1]. Given the scope of the problem and because at the time of this writing there is no vaccine to prevent infection or proven therapy to treat it, attention is understandably riveted on mitigating the immediate health and economic consequences of COVID-19. Elected officials, community leaders, health care providers, and scientists are scrambling to respond to the expanding spread of disease in the United States and elsewhere around the world. At a time when society's efforts are necessarily focused on our acute response to this pandemic, it may seem wrongheaded to think about longer-term strategies in response to SARS-CoV-2. But arguably there is benefit in planning beyond immediate needs and circumstances. Said consideration derives from the fact that even after the current wave of this pandemic subsides, we will not have eradicated SARS-CoV-2. Nor will we be spared from future pandemics of other viruses, whether they be respiratory, enteric or bloodborne.

What can history teach us about successful responses to past infectious disease pandemics? Given the widespread implementation of social distancing (also known by the more accurate designation of "physical distancing") in response to COVID-19 disease, public health leaders are deeply interested in the outcomes of these same so-called "nonpharmaceutical interventions" when they were deployed in response to another deadly pandemic of a respiratory virus, the influenza epidemic of 1918-1919 [2]. Contemporary analyses support the fact that these interventions, when implemented early and in a sustained manner, were successful in mitigating the consequences of pandemic influenza in

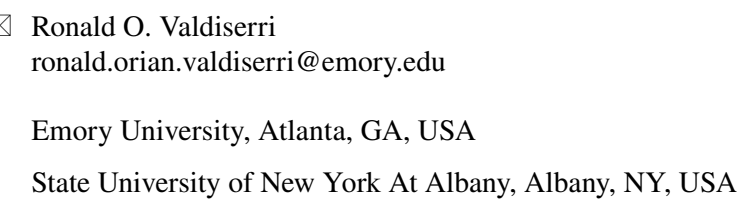

the last century [3]. That valuable information is being put to good use during the current wave of SARS-CoV-2. But what can we say about the public health responses that were undertaken in the years following the 1918-1919 influenza pandemic, after the immediate threat had passed? Certainly, there was increased research interest into the causative agent of influenza, leading to the eventual isolation of influenza A from human tissue samples in 1933 [4]. And historians have noted that the lack of a national disease reporting system in the U.S.- - which hindered a coordinated response to the influenza outbreak of 1918/1919 - was rectified several years later; by 1925 all U.S. states were participating in a national system to report disease [5]. But given the periodicity of influenza, it's come-and-go nature, some experts have opined that our national response to pandemics typically follows a cycle of "panic-neglect-panic-neglect" [6]. Sadly, this supposition is supported by patterns of public health funding in the U.S. Typically, after a national disease outbreak or other disaster there is an infusion of one-time supplemental funding which generally recedes after the emergency wanes and the attention of legislators turns to other, more immediate issues [7].

When faced with a pandemic of a novel infectious disease, it's understandable that we quickly focus on the necessary biomedical tools required to prevent, diagnose, and treat the offending pathogen. Do we have a test that can accurately diagnose infection? How long will it take for scientists to develop an effective vaccine that can prevent disease acquisition? Are any drugs available that can cure or safely treat persons once they've become infected? To be sure, each one of these elements-accurate diagnostic test, effective vaccine, successful treatment-is critical but by themselves they do not constitute an adequate pandemic response. Why? Because, simply stated, a pandemic's impact is not just experienced at the level of the infected individual. By their very nature, pandemics adversely affect large segments of the population, thereby generating negative consequences that spread across social systems and structures. It follows, then, that successful responses to pandemics must include the implementation of societal-level responses and system-wide 
interventions. To wit, during a pandemic the goal of public health is to protect the health of the entire population, not just to prevent or treat disease among specific individuals.

Consider the following scenarios. The most accurate diagnostic test will be of little value without a stable system to deliver it in a timely manner to everyone in need-or a sufficiently scaled workforce that's been trained to properly collect and analyze the large influx of specimens. Without strong community partnerships to amplify health communication messages coming from public health leaders, panic and misinformation can scuttle the uptake of strategies meant to keep communities safe. For example, a handful of anecdotal reports about negative reactions to a new vaccine could impede community uptake, resulting in substantial missed opportunities for immunization. And even curative treatments will be of little value if large segments of the population in need of them are uninsured or underinsured and unable to afford the therapy [8]. Each of these scenarios point out that effective biomedical tools, by themselves, cannot end epidemics. In addition to effective tools and interventions we need surveillance systems to assess and target their need; viable community partnerships across all segments of the public health system to assure that interventions are delivered in a timely, equitable and culturally competent manner; policies, processes and information systems that can continuously monitor the interventions' impact; and a standing public health workforce of sufficient size that is properly equipped and capable of providing these services, in collaboration with other community partners.

If one needs proof of the importance of developing and sustaining system-level interventions to meet the ongoing threat of global pandemics, our nation's response to HIV/ AIDS provides such evidence. To be clear, this comparison is made in reference to our nation's eventual response to HIV—not to its initial response, which was typified largely by denial. Early on, most legislators and policy makers ignored the emerging AIDS epidemic, characterizing it as the consequence of unhealthy behaviors practiced by homosexual men and persons who inject illicit drugs [9]. But a cadre of fearless community activists and farsighted public health leaders were eventually able to push forward a comprehensive agenda that resulted in long term funding for surveillance systems to monitor the spread of disease [10], community-based systems to test for and prevent HIV infection among the vulnerable [11] and a national system to provide comprehensive medical care, essential support services and needed medications for uninsured and underinsured persons living with HIV - the Ryan White HIV/AIDS Program [12]. Nor should we overlook America's substantial contribution to fighting the global spread of HIV. In 2003 the United States government implemented PEPFAR, the largest global health program devoted to a single disease, credited with saving millions of lives globally [13].
True, we have not vanquished HIV from our world, but we have made substantial progress in preventing its spread and improving health outcomes for those who are living with the virus-even in the absence of a vaccine or curative treatment. Our national progress has been such that the United States has now set a goal to reduce new HIV infections by $75 \%$ come 2025 [14]. Without denying the importance of prophylaxis that can prevent the acquisition of HIV [15] or the impact of effective treatments that can reduce viral load such that the risk of sexual transmission is essentially nil [16], we would not be able to realistically visualize the end of AIDS in the United States without the continued public investment in systems that are necessary to prevent infection, improve health outcomes for those living with HIV and monitor changes in disease spread and outcome. Which brings us back to the point of this commentary. We must not allow ourselves to fall into a cycle of "neglect" by ignoring the threat of future pandemics once this initial wave of SARS-CoV-2 has passed.

Our national response to HIV/AIDS has shown us that in addition to funding the biomedical enterprise so that it can deliver effective treatments (including an eventual vaccine), we must also invest in a strong, stable public health system that is ready to respond when calamities like COVID-19 hit [17]. Addressing chronic underfunding in state and local health departments is key to that effort $[18,19]$. Nor should we ignore the vital role that non-governmental organizations - especially community-based organizations — can play when they work in partnership with public health agencies. In the United States and across the world, NGOs have been a critical component in successful efforts to prevent and treat HIV [20]. And adequately funded HIV surveillance systems in the U.S.- - a rarity among other infectious diseases like hepatitis $\mathrm{C}$ virus (HCV)—have provided increasingly detailed information that enable us to quickly identify emerging outbreaks and accurately target prevention and care services to underserved areas.

We readily admit that the epidemiology, transmission dynamics and pathogenesis of these two viruses-HIV and SARS-CoV-2-are vastly different. Nor do we mean to infer that the interventions successful in preventing HIV can be directly applied to COVID-19 disease. But the principles that we've learned from decades of grappling with the HIV pandemic - in the U.S. and abroad — are relevant in regard to developing successful, long-term responses to protect against other infectious disease pandemics. While maintaining an adequate public health infrastructure may "top the list" of necessities when it comes to protecting population health, other fundamental principles, listed below, are equally important.

Sustained investment in public health infrastructure is necessary in order to develop, implement and evalu- 
ate effective system-level interventions in response to emerging and ongoing health threats.

Approaches to assuring and preserving health must not be limited to the biomedical sciences; we must also actively address the psychosocial influences that affect well-being.

Affected communities must be actively engaged in identifying and implementing strategies in response to threats to their health and well-being.

Stigma and fear are constant companions of infectious disease pandemics; proactive steps must be taken to minimize their negative consequences.

To reduce health disparities, proactively identify groups and communities at disproportionate risk of developing disease or poor health outcomes and design interventions to reduce these disparities and to promote health equity.

In recognition of the interconnected nature of our world, there must be a global component in our response to infectious disease pandemics and this component must be based on the best available information and science.

Let's be sure to put the hard-won knowledge that we've acquired from our decades-long interaction with the HIV/ AIDS pandemic into practice as we prepare for the future of COVID-19 and other pandemics that have yet to emerge. To paraphrase Santayana, failure to learn from our past can only ensure repeated failure in our future.

\section{References}

1. McNeil DG. Coronavirus Has Become a Pandemic, W.H.O. Says. New York Times. 2020. http://www.nytimes.com/2020/03/11/ health/coronavirus-pandemic-who.html

2. Aimone F. The 1918 influenza epidemic in New York City: a review of the public health response. Public Health Rep. 2010;125(Suppl 3):71-9.

3. Markel H, Lipman HB, Navarro JA, et al. Nonpharmaceutical interventions implemented by US cities during the 1918-1919 influenza pandemic. JAMA. 2007;298(6):644-54.

4. Kamradt-Scott A. Changing perceptions of pandemic influenza and public health responses. Am J Public Health. 2012;102(1):90-8.

5. Spinney L. How the 1918 Flu Pandemic Revolutionized Public Health. Smithsonian Magazine. 2017. http://www.smithsonia nmag.com/history/how-1918-flu-pandemic-revolutionized-publi c-health-180965025/
6. Greenberger M. Better prepare than reach: reordering public health priorities 100 years after the Spanish Flu epidemic. Am J Public Health. 2018;108(11):1465-8.

7. Faberman RK, Lieberman DA, McKillop M. Ready or not: protecting the public's health from diseases, disasters, and bioterrorism. Trust for America's Health. 2020. http://www.tfah.org/repor t-details/readyornot2020/

8. Ward JW, Mermin JH. Simple, effective but out of reach? Public health implications of HCV drugs. New Engl J Med. 2015;373(27):2678-80.

9. Valdiserri RO. HIV/AIDS in Historical Profile. In: Valdiserri RO, editor. Dawning answers: how the HIV/AIDS epidemic has helped to strengthen public health. New York: Oxford University Press; 2003.

10. Buehler JW. HIV and AIDS surveillance: public health lessons learned. In: Valdiserri RO, editor. Dawning answers: how the HIV/AIDS epidemic has helped to strengthen public health. New York: Oxford University Press; 2003.

11. Fenton KA, Valdiserri RO. Twenty-five years of HIV/ AIDS-United States, 1981-2006. Morb Mortal Weekly Rep. 2006;55(21):585-9.

12. Health Resources and Services Administration. About the Ryan White HIV/AIDS Program. https://www.hab.hrsa.gov/about-ryanwhite-hivaids-program/about-ryan-white-hivaids-program

13. Kaiser Family Foundation. The U.S. President's Emergency Plan for AIDS Relief (PEPFAR). 2019 Nov 25. http://www.kff. org/global-health-policy/fact-sheet/the-U-S-presidents-emerg ency-plan-for/\#

14. Fauci AS, Redfield RR, Sigounas G, Weahkee MD, Giroir BP. Ending the HIV epidemic: a plan for the United States. JAMA. 2019;321(9):844-5.

15. Grant RM, Lama JR, Anderson PL, et al. Preexposure chemoprophylaxis for HIV prevention in men who have sex with men. N Engl J Med. 2010;363:2587-99.

16. Rodger AJ, Cambiano V, Bruun T, et al. Sexual activity without condoms and risk of HIV transmission in serodifferent couples when the HIV-positive partner is using suppressive antiretroviral therapy. JAMA. 2016;316(2):171-81.

17. DeSalvo K, Parekh A, Hoagland W, et al. Developing a financing system to support public health infrastructure. Am J Public Health. 2019;109(10):1358-61.

18. Daschle T, Frist B, von Eschenbach A. America's Public Health Infrastructure needs Consistent Funding. Roll Call. 2020. http:// www.rollcall.com/2020/03/14/americas-public-health-infrastruc ture-needs-consistent-funding/

19. McKillop M, Ilakkuvan V. The Impact of Chronic Underfunding on America's Public Health System: Trends, Risks, and Recommendations, 2019. Trust for America's Health. 2019. http://www. tfah.org/report-details/2019-funding-report/

20. Valdiserri RO, Holtgrave DR. Ending HIV in America: not without the power of community. AIDS Behav. 2019;23(11):2899-903.

Publisher's Note Springer Nature remains neutral with regard to jurisdictional claims in published maps and institutional affiliations. 